\title{
IDENTIFICATION AND MOLECULAR CHARACTERISATION OF ESBL PRODUCING UROPATHOGENIC ESCHERICHIA COLI STRAINS ISOLATED FROM A TERTIARY CARE HOSPITAL OF TRIPURA
}

\author{
Arunabha Dasgupta1, Tapan Majumdar², Rajesh Bhowmik ${ }^{3}$
}

${ }_{1}^{1}$ Associate Professor, Department of Medicine, Agartala Government Medical College, Agartala, Tripura, India.

${ }^{2}$ Associate Professor, Department of Microbiology, Agartala Government Medical College, Agartala, Tripura, India.

3Junior Research Fellow, Department of Medicine, Agartala Government Medical College, Agartala, Tripura, India.

\section{ABSTRACT}

\section{BACKGROUND}

Infections caused by Escherichia coli (E. coli) have become a significant worldwide public health problem. Furthermore, the situation is worsening due to advent of increased antibiotic resistance due to the evolution of plasmid mediated multi-resistant antibiotic genes, mainly Extended Spectrum B-lactamases (ESBLs). These enzyme producing organisms are also co-resistant to other different classes of antibiotics.

Aims and Objectives- The aim of the study was to determine the antibiotic resistance pattern of Uropathogenic E. coli isolated from tertiary care hospital of Tripura with an objective of plasmid profiling of multidrug resistant isolates and to determine the blaTEM and blacTX-м producers by molecular methods, mainly by PCR using gene specific primer.

\section{MATERIALS AND METHODS}

This study was undertaken to identify the presence of ESBLs enzyme by phenotypic method and presence of bla TEM and bla among the ESBL-producing Uropathogenic Escherichia coli (UPEC) by polymerase chain reaction using gene specific primers at our setup.

\section{RESULTS}

Out of 150 clinical isolates from patients of the tertiary care hospital, 85 strains were identified as E. coli strains. These isolates were further screened for ESBL production by phenotypic methods using drug-inhibitor combination disks, namely ceftazidimeclavulanate $(30+10 \mu \mathrm{g})$ and cefotaxime-clavulanate $(30+10 \mu \mathrm{g})$ as per CLSI guidelines. Out of 85 isolates, 52 were detected as ESBL producers. Further analysis for plasmid isolation showed that all of them harbour plasmids of size ranging from $\sim 0.5$ to $20 \mathrm{~kb}$. Molecular analysis of ESBL gene indicated predominance of bla TEм $42 \%$ followed by bla +bla

\section{CONCLUSION}

This study highlights increased proportion of ESBL producers among uropathogenic E. coli isolated from the tertiary care setup of Tripura. These ESBL producers were simultaneously resistant to three or more than three groups of other antibiotics and were assigned as multidrug resistant (MDR) E. coli. The isolates harboured plasmids of varied size and numbers. Molecular analysis of

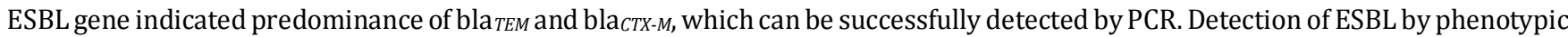
tests if supplemented with molecular methods may provide a valuable diagnostic and research tool. These will strengthen the antibiotic stewardship programme of the hospital and aid in preserving the efficacy of life saving antibiotics.

\section{KEY WORDS}

Escherichia coli, Anti-Bacterial Agents, Tertiary Care Centre, Drug Resistance, Urinary Tract Infections, Plasmids, DNA, Polymerase Chain Reaction.

HOW TO CITE THIS ARTICLE: Dasgupta A, Majumdar T, Bhowmik R. Identification and molecular characterisation of ESBL producing uropathogenic escherichia coli strains isolated from a tertiary care hospital of Tripura. J. Evolution Med. Dent. Sci. 2018;7(24):2829-2833, DOI: 10.14260/jemds/2018/638

\section{BACKGROUND}

Urinary tract infection (UTI) is a common bacterial disease.[1] E. coli is reported to be the major cause (85\% - 95\%) of urinary tract infection. ${ }^{[2]}$ The treatment of choice for urinary tract infections are uses of specific antibiotics.

'Financial or Other Competing Interest': Dr. Majumdar reports grants from Department of Biotechnology (DBT), outside the submitted work. Submission 30-04-2018, Peer Review 24-05-2018,

Acceptance 31-05-2018, Published 11-06-2018.

Corresponding Author:

Dr. Tapan Majumdar,

Associate Professor,

Department of Microbiology,

Agartala Government Medical College,

PO. Kunjaban-799006, Tripura, India.

E-mail:drtapan1@rediffmail.com,drtapan1960@gmail.com DOI: $10.14260 /$ jemds/2018/638

\section{(c) (i) $(9)$}

However, injudicious uses of antibiotics exert selective pressure on the bacteria causing emergence of resistant strains to multiply and spread. Therefore, multidrug resistant (MDR) organisms are frequently found in urinary tract infection. [3] Successful antibiotic therapy against Uropathogenic $E$. coli is often impaired due to the resistance to commonly used antimicrobial agents. ${ }^{[4]}$

$\beta$-lactams are the most commonly used antibiotic in hospitals and community setup resulting in increased morbidity, mortality and health-care costs because of emergence of resistant strain.[5] This is due to the production of $\beta$-lactamases followed subsequently by the evolution of extended spectrum $\beta$-lactamases [ESBLs]. Extended spectrum $\beta$-lactamases are a large, rapidly evolving group of plasmidmediated enzymes capable of hydrolysing and inactivating penicillins, cephalosporins and monobactams and are inhibited by $\beta$-lactamase inhibitors such as clavulanate, 
sulbactam and tazobactam. ${ }^{6,7,8]}$ Detection of ESBLs are not routinely done in resource poor setup.

This study was undertaken to identify the presence of ESBLs enzyme by phenotypic method and presence of blaтEM and blaстх-м gene among the ESBL-producing Uropathogenic Escherichia coli (UPEC) by polymerase chain reaction using gene specific primers at our setup.

\section{MATERIALS AND METHODS \\ Identification of Organisms}

Midstream urine samples received in the department were inoculated CLED agar plates. These plates were incubated at $37^{\circ} \mathrm{C}$ aerobically and after overnight incubation they were checked for bacterial growth. The organisms were identified by their colony morphology, staining characters, pigment production, motility and other relevant biochemical tests as per standard laboratory protocol.[9,10]

\section{Antimicrobial Susceptibility Test done by Modified Kirby- Bauer Sensitivity Testing/ Method}

As per CLSI guidelines, modified Kirby-Bauer sensitivity testing method was used for this purpose.[11] Bacterial suspension having visually equivalent turbidity to 0.5 McFarland standards were inoculated in Mueller-Hinton agar media using swab stick. Inoculated plates were incubated at $37^{\circ} \mathrm{C}$ for 24 hours. The next day plates were read by taking measurement of zone of inhibition. Antimicrobial discs were used for Amikacin (30 $\mu \mathrm{g})$, Amoxyclav (30 $\mu \mathrm{g}$ ), cephotaxime (30 $\mu \mathrm{g})$, Ceftazidime $(30 \mu \mathrm{g})$, Ciprofloxacin $(5 \mu \mathrm{g})$, nitrofurantoin $(300 \mu \mathrm{g})$, ofloxacin $(5 \mu \mathrm{g})$ Piperacillin $(75 \mu \mathrm{g})$, Cefotaxime/ clavulanic acid (30/10 $\mu \mathrm{g})$, Ceftazidime/clavulanic acid $\quad(30 / 10 \quad \mu \mathrm{g})$, Piperacillin/Tazobactam (100/10 $\mu \mathrm{g})$.

\section{Confirmatory Test for ESBLs \\ Double Disk Diffusion Method (DDDT)}

For this test as per CLSI document M-100 S-25, lawn culture of the test isolates inoculated on Mueller-Hinton agar plate followed by putting up of disc of ceftazidime (30 $\mu \mathrm{g})$, cefotaxime $(30 \mu \mathrm{g})$ alone and a disc of ceftazidime and cefotaxime in combination with clavulanic acid (30/10 $\mu \mathrm{g})$, the discs were placed $25 \mathrm{~mm}$ apart, Center to Center and incubated overnight at $37^{\circ} \mathrm{C}$. $\mathrm{A} \geq 5 \mathrm{~mm}$ increase in zone diameter for either antimicrobial agent tested in combination with clavulanic acid versus its zone when tested alone was designated as ESBL positive.[12]

\section{Determination of Minimum Inhibitory Concentration (MIC) by Macro Broth Dilution Method Preparation of Inoculum}

- Broth suspension of isolated colonies selected from an 18- to 24-hour agar plate were used to prepare the inoculum by making turbidity equivalent to a 0.5 McFarland, which is approximately equivalent to 1 to $2 \mathrm{x}$ $10^{8}$ colony forming units (CFU) $/ \mathrm{mL}$.

- This suspension was further diluted to adjust the inoculum to contain approximately $5 \times 10^{5} \mathrm{CFU} / \mathrm{mL}$. This was accomplished by diluting the 0.5 McFarland suspensions 1: 150 , resulting in a tube containing approximately $1 \times 10^{6} \mathrm{CFU} / \mathrm{mL}$. The subsequent 1: 2 dilution in step 3 brings the final inoculum to $5 \times 10^{5}$ $\mathrm{CFU} / \mathrm{mL}$. ${ }^{[13]}$

\section{Inoculation}

$1 \mathrm{~mL}$ of the adjusted inoculum added to each tube containing $1 \mathrm{~mL}$ of antimicrobial agent in the dilution series (and a positive control tube containing only broth) and mixed. This results in a 1: 2 dilution of each antimicrobial concentration and a 1: 2 dilution of the inoculums.

\section{Incubation}

Tubes were incubated at $35^{\circ} \mathrm{C}$ for 16 to 20 hours in an ambient air incubator.

\section{Interpretation}

The lowest concentration at which the isolate was completely inhibited (as evidenced by the absence of visible bacterial growth) was recorded as the minimal inhibitory concentration or MIC.

\section{Genotypic Detection}

\section{A) Preparation of Plasmid DNA}

A pure colony of each isolate was inoculated from CLED agar into $5 \mathrm{~mL}$ of Luria-Bertani broth and incubated for $20 \mathrm{~h}$ at $37^{\circ} \mathrm{C}$. Cells from the overnight culture were harvested by centrifugation at $12,000 \mathrm{rpm}$ for 5 mins. Plasmid DNA were isolated by alkaline lysis method. The DNA samples were stored at $-20^{\circ} \mathrm{C}$ until used.[14]

\section{B) Profiling of Plasmid}

\section{1) Preparation of Agarose Gel}

$0.8 \mathrm{gm}$ agarose in $100 \mathrm{~mL}$ of diluted TAE buffer was prepared by using a microwave oven. The melted agarose was allowed to cool at $50^{\circ} \mathrm{C}$ and $20 \mu \mathrm{L}$ ethidium bromide was mixed and poured into gel tray after shaking and combs were placed. After solidification of the gel, the comb was removed. During electrophoresis, the gel was placed in a horizontal electrophoresis apparatus containing TAE buffer and ethidium bromide.

\section{2) Gel Electrophoresis of the Sample}

The mixture containing $5 \mu \mathrm{L}$ of sample and $2.0 \mu \mathrm{L}$ of loading buffer was slowly loaded into the well using disposable micropipette tips. $100 \mathrm{bp}$ molecular weight marker was loaded in one well to determine the size of the amplified PCR products. Electrophoresis was carried out at 100 volts for 35 minutes.

\section{3) Gel Documentation}

The products electrophoresis was visualised by transilluminator followed by photographed transferring of data to a computer for further analysis.

\section{C) Detection of bla}

PCR amplification of bla TEM and blactX-M genes was done following the published protocol of Mukherjee et al.[15] Briefly, Primers used to detect blaTEM specific gene were 5' ATGAGTATTCAACATTTCCGTG-3' (forward primer) and 5'TTACCAATGCTTAATCA GTGAG-3' (reverse primer) and for blaCTX-M gene, a degenerate primer set comprising of forward primer: 5' ATGYGCAGYACCAGTAAG 3' (Y represents T/C) and reverse primer: 5' ATATCRTTGGTGGTGCCRT 3' (R represents $A / G$ ) procured from Integrated DNA Technologies Pte. Ltd. (IDT), USA through BioApps. The extracted plasmid DNA was used as the template in the PCR reaction. PCR mix 
was prepared for a final reaction volume of $20 \mu \mathrm{L}$ using $\mathrm{H}_{2} \mathrm{O}$ (Milli-Q grade), 50 pmol and 20 pmol of blaCTX-M and blaTEM gene specific primers respectively, $250 \mu \mathrm{M}$ of each $\mathrm{dNTP}, 1.5$ units of Taq polymerase, $2.0 \mu \mathrm{L}$ of $10 \mathrm{X}$ PCR buffer containing $1.5 \mathrm{mM} \mathrm{MgCl}_{2}$ and $100 \mathrm{ng}$ DNA template. Initial denaturation at $94^{\circ} \mathrm{C}$ for 3 mins followed by 30 cycles of denaturation at $94^{\circ} \mathrm{C}$ for 30 secs, annealing at $52^{\circ} \mathrm{C}$ for 30 secs and elongation at $72^{\circ} \mathrm{C}$ for $1 \mathrm{~min}$ was carried out in a thermocycler. The final elongation step was extended to $10 \mathrm{mins}$ at $72^{\circ} \mathrm{C}$. The amplified products were separated in agarose gel containing ethidium bromide $(0.5 \mathrm{mg} / \mathrm{mL})$. To measure the molecular weights of amplified products, $100 \mathrm{bp}$ DNA ladder was used. The images of ethidium bromide stained DNA bands were visualised and documented using a gel documentation system.[15,16,17]

\section{RESULTS}

150 clinical isolates from patients of the tertiary care hospital, Agartala, Tripura were included in the study. Out of these 85 strains were identified as Escherichia coli, 40 strains as Klebsiella pneumoniae, 14 strains as Enterobacter species, 8 strains as Pseudomonas species and 3 strains as Acinetobacter species.

Antibiogram of the $E$. coli isolates shows $79.36 \%$ sensitive to Nitrofurantoin followed by Amikacin $74.36 \%$, Ofloxacin $60.31 \%$, Ceftazidime $52.38 \%$, Cefotaxime $44.44 \%$, Amoxyclav54\%, Ciprofloxacin 28.57\% Piperacillin 38.01\%, PiperacillinTazobactam $81.71 \%$ percent respectively which is shown in Fig. 1.

Phenotypic analysis by DDDT (Fig. 2) shows 61\% (52/85) are confirmed ESBL producer and 39\% (33/85) are $\beta$ lactamase inhibitor resistant (BLIR). Minimal inhibitory concentration (MIC) studies using macro broth dilution method against ceftazidime and cefotaxime on the ESBL and BLIR isolates indicated that the average values of the ESBL producers were $<512 \mu \mathrm{g} / \mathrm{mL}$ and BLIR were $>512 \mu \mathrm{g} / \mathrm{mL}$ respectively as shown in Table 1.

Plasmids were extracted from all 52 clinical isolates of E.coli and used as template in PCR to identify the $\beta$-lactamase genes. All the isolates were found to harbour plasmids, size ranging from $\sim 0.5$ to $20 \mathrm{~kb}$. Molecular analysis of ESBL gene shown in Fig. 3 indicated predominance of bla TEM $42 \%$ followed by bla +bla TEм $8 \%$ respectively, which is shown in Table 2 .

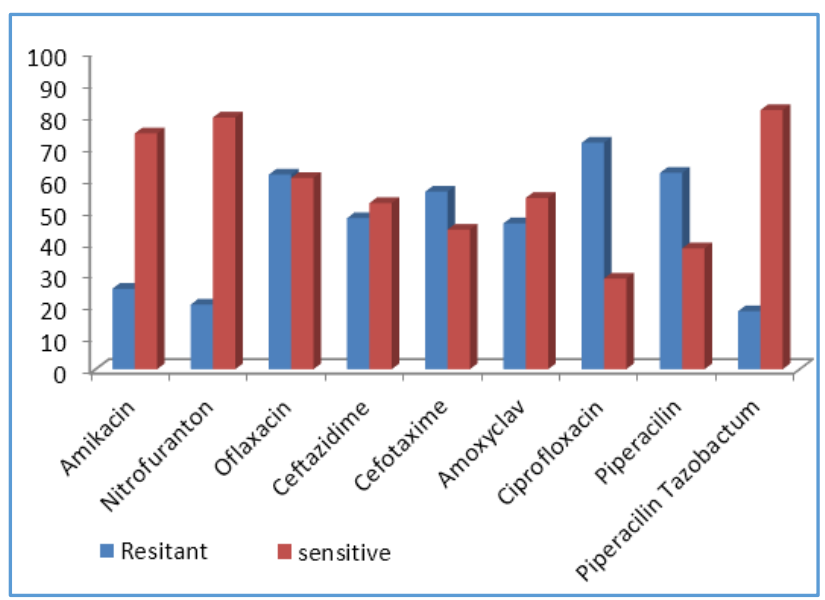

Figure 1. Antibiogram of Escherichia coli Isolates $(n=85)$ recovered from UTI Patients

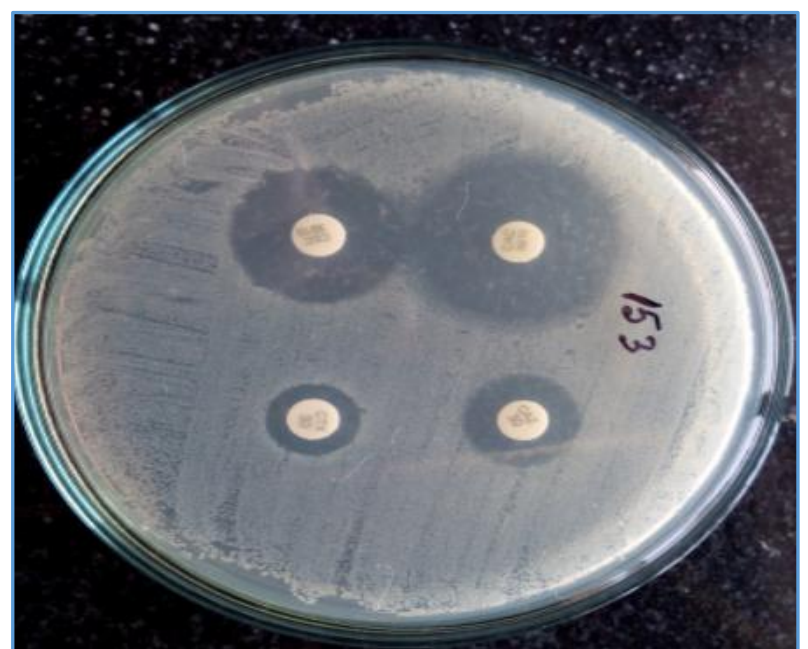

Figure 2. Showing Double Disc Diffusion Test (DDDT)

\section{*Interpretation}

An increase of $\geq 5 \mathrm{~mm}$ in inhibition zone diameter around combination disk of Ceftazidime + Clavulanic acid against the inhibition zone diameter around Ceftazidime disk alone confirms ESBL production.

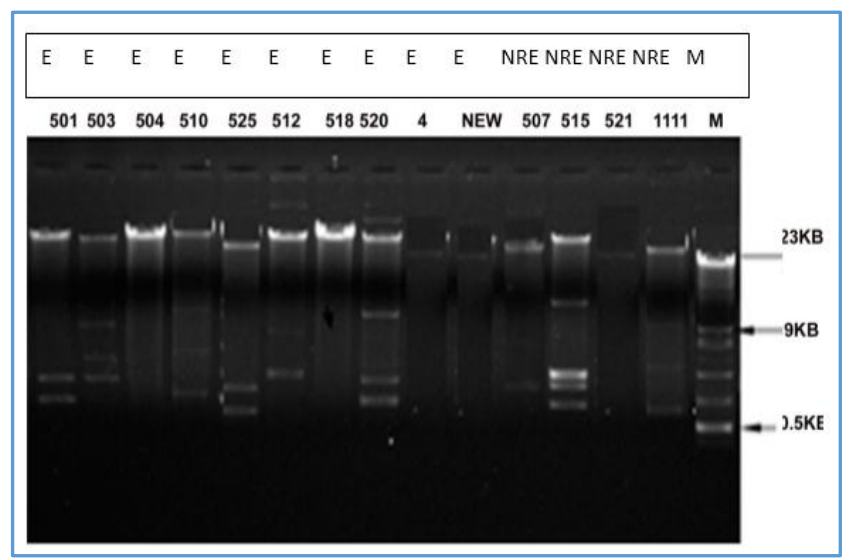

Figure 3. PCR Results of Extracted Plasmid DNA

${ }^{*}$ E- ESBL producer, NRE- $\beta$-lactamase inhibitor resistant, NE- susceptible to cephalosporins.

\begin{tabular}{|c|c|c|c|c|}
\hline \multirow{2}{*}{$\begin{array}{c}\text { Dilution } \\
\text { Range } \\
(\mu \mathrm{\mu g} / \mathrm{mL})\end{array}$} & $\begin{array}{c}\text { Cefotaxime } \\
\text { Positive } \\
(n=52)\end{array}$ & $\begin{array}{c}\text { ESBL } \\
\text { Negative } \\
(\boldsymbol{n}=\mathbf{3 3})\end{array}$ & $\begin{array}{c}\text { ESBL } \\
\text { Positive } \\
(\boldsymbol{n}=\mathbf{5 2})\end{array}$ & $\begin{array}{c}\text { Ceftazidime } \\
\text { Negative } \\
(\boldsymbol{n}=\mathbf{3 3})\end{array}$ \\
\hline$\leq 0.25$ & - & - & - & - \\
\hline 0.5 & - & - & - & - \\
\hline 1 & - & - & - & - \\
\hline 2 & - & - & - & \\
\hline 4 & - & - & - & - \\
\hline 8 & - & - & - & - \\
\hline 16 & - & - & - & - \\
\hline 32 & - & - & - & - \\
\hline 64 & 08 & - & 07 & - \\
\hline 128 & 21 & - & 27 & - \\
\hline 256 & 23 & - & 18 & - \\
\hline 512 & - & 17 & - & 23 \\
\hline 1024 & - & 19 & - & 10 \\
\hline Table 1. Detection of MIC Values in ESBL producers and \\
Non-ESBL producer by Macro Broth Dilution Method \\
\hline \multicolumn{7}{|r|}{}
\end{tabular}




\begin{tabular}{|c|c|}
\hline $\begin{array}{l}\beta \text {-Lactamase } \\
\text { Genes }\end{array}$ & ESBL producing E. coli \\
\hline bla $T E M$ & $42 \%(22 / 52)$ \\
\hline bla $C T X-M$ & $35 \%(18 / 52)$ \\
\hline bla $O X A+$ bla $T E M$ & $15 \%(8 / 52)$ \\
\hline blatEM + bla $c T X-M$ & $8 \%(4 / 52)$ \\
\hline \multicolumn{2}{|c|}{$\begin{array}{l}\text { Table 2. } \beta \text {-Lactamase Genotypes in ESBL }(n=52) \\
\text { producing Uropathogenic E. coli Isolates }\end{array}$} \\
\hline
\end{tabular}

\section{DISCUSSION}

This study highlights increased proportion of ESBL producers among uropathogenic $E$. coli isolated from the tertiary care setup of Tripura. These ESBL producers were simultaneously resistant to three or more than three groups of other antibiotics and were assigned as MDR.

E. coli- These MDR E. coli exhibited simultaneous resistance to large number of antibiotics like Ciprofloxacin, Amoxyclav, Ciprofloxacin, Ceftazidime, Ofloxacin and Cefotaxime. Whereas Amikacin, Piperacillin/Tazobactam and Nitrofurantoin were found to be the most active antimicrobials against these organisms. The isolates harboured plasmids of varied size and numbers. Molecular analysis of ESBL gene indicated predominance of blaтем and blaстх-м, which could be successfully detected by PCR.

Clinical Microbiology laboratories should report about the ESBLs phenotypes, which may help clinician to be aware and alert about choosing both empirical and targeted antibiotic therapy against uropathogenic E. coli. At the same time, molecular characterisation of these ESBL producers will assist in understanding the pathogenesis as well as management of UTI. Similar study by Grover et al emphasised about molecular detection, where facilities are available.[18] Molecular characterisation also help in detecting exact ESBLs subtypes that cannot be detected by phenotypic analysis.[19,20] Detection of ESBLs by phenotypic tests if supplemented with molecular methods may provide a valuable diagnostic and research tool. These will strengthen the antibiotic stewardship programme of the hospital and aid in preserving the efficacy of life saving antibiotics.

\section{CONCLUSION}

ESBL producers among uropathogenic $E$. coli isolated from the tertiary care set-up of Tripura are on the rise. These ESBL producers were simultaneously resistant to three or more than three categories of other antibiotics and were designated as MDR E. coli. Plasmids of varied size and numbers were responsible for carrying the genes of drug resistance. Molecular analysis of ESBL gene indicated predominance of bla тем $42 \%$ followed by bla стх-м $35 \%$, blaOXA + bla тем $15 \%$ and bla $_{C T X-M}+$ bla $_{T E M} 8 \%$ respectively. Detection of ESBLs by phenotypic tests if supplemented with molecular methods may provide a valuable diagnostic and research tool. These will strengthen the antibiotic stewardship programme of the hospital and aid in preserving the efficacy of life saving antibiotics.

\section{ACKNOWLEDGEMENTS}

The authors wish to acknowledge DBT (Department of Biotechnology New Delhi, India) for financial support and grant of the project, Dr. Mandira Mukherjee, Associate Professor, Department of Biochemistry and Medical Biotechnology, Calcutta School of Tropical Medicine, Kolkata, West Bengal, India and other staff of Microbiology
Department, AGMC (Agartala Govt. Medical College) for their kind cooperation.

\section{REFERENCES}

[1] Dromigny JA, Nabeth P, Juergens-Behr A, et al. Risk factors for antibiotic-resistant Escherichia coli isolated from community-acquired urinary tract infections in Dakar, Senegal. J Antimicrob Chemother 2005;56(1):236-9.

[2] Russo TA, Johnson JR. Medical and economic impact of extraintestinal infections due to Escherichia coli: focus on an increasingly important endemic problem. Microbes Infect 2003;5(5):449-56.

[3] Calbo E, Romani V, Xercavins M, et al. Risk factors for community-onset urinary tract infections due to Escherichia coli harbouring extended-spectrum betalactamases. J Antimicrob Chemother 2006;57(4):7803.

[4] Chakupurakal R, Ahmed M, Sobithadevi DN, et al. Urinary tract pathogens and resistance pattern. J Clin Pathol 2010;63(7):652-4.

[5] Maiti SN, Phillips OA, Micetich RG, et al. Beta-lactamase inhibitors: agents to overcome bacterial resistance. Curr Med Chem 1998;5(6):441-56.

[6] Ndugulile F, Jureen R, Harthug $S$, et al. Extended spectrum lactamases among Gram-negative bacteria of nosocomial origin from an Intensive Care Unit of a tertiary health facility in Tanzania. BMC Infect Dis 2005;5:86.

[7] Spanu T, Sanguinetti M, Tumbarello M, et al. Evaluation of the new VITEK 2 extended-spectrum beta-lactamase (ESBL) test for rapid detection of ESBL production in Enterobacteriaceae isolates. J Clin Microbiol 2006;44(9):3257-62.

[8] Hosoglu S, Gundes S, Kolayli F, et al. Extended-spectrum beta-lactamases in Ceftazidime-resistant Escheriachia coli and Klebsiella pneumoniae isolates in Turkish hospitals. Indian J Med Microbial 2007;25(4):346-50.

[9] Versalovic J, Carroll KC, Funke G. Manual of clinical microbiology. $10^{\text {th }}$ edn. Washington, DC: American Society of Microbiology 2011.

[10] Mukherjee M, Basu S, Mukherjee SK, et al. Multidrugresistance and extended spectrum beta-lactamase production in uropathogenic E. Coli which were Isolated from Hospitalized Patients in Kolkata, India. J Clin Diagnos Res 2013;7(3):449-53.

[11] Clinical and Laboratory Standards Institute. M100-S22 Performance Standards for antimicrobial susceptibility testing 21st information supplement. Wayne PA: CLSI 2012.

[12] Bradford PA. Extended-spectrum $\beta$ lactamases in the 21st century: characterization, epidemiology and detection of this important resistance threat. Clin Microbiol Rev 2001;14(4):933-51.

[13] Wiegand I, Hilpert K, Hancock RE. Agar and broth dilution methods to determine the minimal inhibitory concentration (MIC) of antimicrobial substances. Nat Protoc 2008;3(2):163-75.

[14] Carattoli A, Bertini A, Villa L, et al. Identification of plasmids by PCR-based replicon typing. Journal of Microbiological Methods 2005;63(3):219-28. 


\section{Jemds.com}

[15] Mukherjee M, Basu S, Majumdar M. Detection of bla TEM and bla CTX-M genes by multiplex polymerase chain reaction amongst uropathogenic Escherichia coli strains isolated from hospitalized patients in Kolkata, India. Int J Biosci (IJB) 2011;1(6):64-9.

[16] Sorour AE, Wali IE, El-Hodaky SK. OXA-type-betalactamases among extended-spectrum-cephalosporin non-susceptible pseudomonas aeruginosa isolates collected from a large teaching hospital in Cairo. Egypt J Med Microbiol 2008;17(4):565-72.

[17] Lim KT, Yasin R, Yeo CC, et al. Characterization of multidrug resistant ESBL-producing Escherichia coli isolates from hospitals in Malaysia. Article ID 165637, J Biomed Biotechnol 2009;2009: p. 10.

\section{Original Research Article}

[18] Grover SS, Sharma M, Chattopadhya D, et al. Phenotypic and genotypic detection of ESBL mediated cephalosporin resistance in Klebsiella pneumoniae: emergence of high resistance against cefepime, the fourth-generation cephalosporin. J Infect 2006;53(4):279-88.

[19] Trang NH, Nga TV, Campbell JI, et al. The characterization of ESBL genes in Escherichia coli and Klebsiella pneumoniae causing nosocomial infections in Vietnam. J Infect Dev Ctries 2013;7(12):922-8.

[20] Krishnamurthy V, Vijaykumar GS, Kumar SM, et al. Phenotypic and genotypic methods for detection of extended spectrum $\beta$ lactamase producing Escherichia coli and Klebsiella pneumoniae isolated from ventilator associated pneumonia. J Clin Diagn Res 2013;7(9):1975-8. 